\title{
Role of Intact Hydrogen-Bond Networks in Multiproton-Coupled Electron Transfer
}

\author{
Walter D. Guerra, Emmanuel Odella, Maxim Secor, Joshua J. Goings, María N. Urrutia, \\ Brian L. Wadsworth, Miguel Gervaldo, Leónides E. Sereno, Thomas A. Moore, Gary F. Moore,* \\ Sharon Hammes-Schiffer, $*$ and Ana L. Moore*
}

Cite This: https://dx.doi.org/10.1021/jacs.0c10474

Read Online

ACCESS | Lill Metrics \& More | 回 Article Recommendations | st Supporting Information

ABSTRACT: The essential role of a well-defined hydrogen-bond network in achieving chemically reversible multiproton translocations triggered by one-electron electrochemical oxidation/reduction is investigated by using pyridylbenzimidazole-phenol models. The two molecular architectures designed for these studies differ with respect to the position of the $\mathrm{N}$ atom on the pyridyl ring. In one of the structures, a hydrogen-bond network extends uninterrupted across the molecule from the phenol to the pyridyl group. Experimental and theoretical evidence indicates that an overall chemically reversible two-protoncoupled electron-transfer process (E2PT) takes place upon electrochemical oxidation of the phenol. This E2PT process yields the pyridinium cation and is observed regardless of the cyclic voltammo-

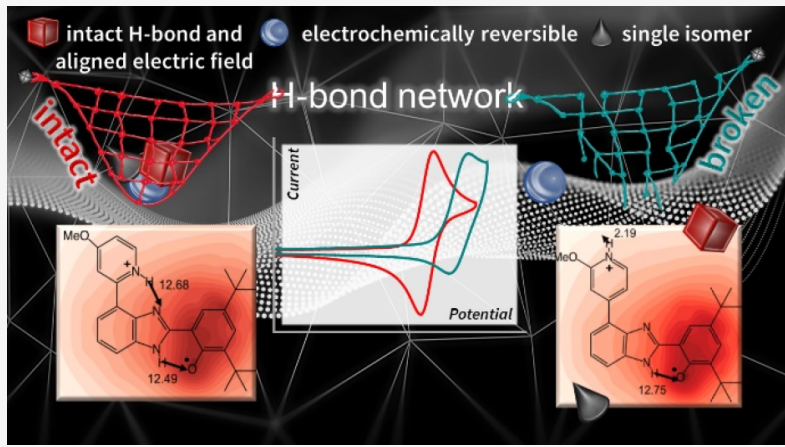
gram scan rate. In contrast, when the hydrogen-bond network is disrupted, as seen in the isomer, at high scan rates $\left(\sim 1000 \mathrm{mV} \mathrm{s}^{-1}\right)$ a chemically reversible process is observed with an $E_{1 / 2}$ characteristic of a one-proton-coupled electron-transfer process (E1PT). At slow cyclic voltammetric scan rates $\left(<1000 \mathrm{mV} \mathrm{s}^{-1}\right)$ oxidation of the phenol results in an overall chemically irreversible two-proton-coupled electron-transfer process in which the second proton-transfer step yields the pyridinium cation detected by infrared spectroelectrochemistry. In this case, we postulate an initial intramolecular proton-coupled electron-transfer step yielding the E1PT product followed by a slow, likely intermolecular chemical step involving a second proton transfer to give the E2PT product. Insights into the electrochemical behavior of these systems are provided by theoretical calculations of the electrostatic potentials and electric fields at the site of the transferring protons for the forward and reverse processes. This work addresses a fundamental design principle for constructing molecular wires where protons are translocated over varied distances by a Grotthuss-type mechanism.

\section{INTRODUCTION}

Photosynthesis powers the earth's biosphere by converting solar energy into chemical energy in the form of biomass. In the early events of photosynthesis, proton-coupled electron transfer (PCET) reactions play key functions. For example, in water splitting by photosystem II (PSII), the involvement of PCET in the operation of the redox relay $\operatorname{Tyr}_{\mathrm{z}}\left(\mathrm{Y}_{\mathrm{z}}\right)$ is associated with the high quantum efficiency of PSII. ${ }^{1-5}$ Bioinspired assemblies have been successful in modeling $\mathrm{Y}_{\mathrm{Z}}$ and its hydrogen-bonded partner histidine $190\left(\mathrm{Y}_{\mathrm{Z}}-\mathrm{H} 190\right){ }^{6-13}$ demonstrating PCET processes capable of competing effectively with the recombination of photoinitiated charge separation. $^{14,15}$

The unsubstituted benzimidazole-phenol (BIP) (1, Chart 1) was designed as a platform for the study of PCET, where the benzimidazole moiety models $\mathrm{H} 190$ and the phenol models $\mathrm{Y}_{\mathrm{z}}{ }^{16-19}$ In our previous work, ${ }^{20-23}$ a series of substituted BIP derivatives were prepared to better understand the change in Gibbs free energy required to achieve
Chart 1. Molecular Structure of BIP (1) and BIP Substituted with Pyridyl Moieties (2 and 3, Color-Coded as in Figures 2, 3 and 4)

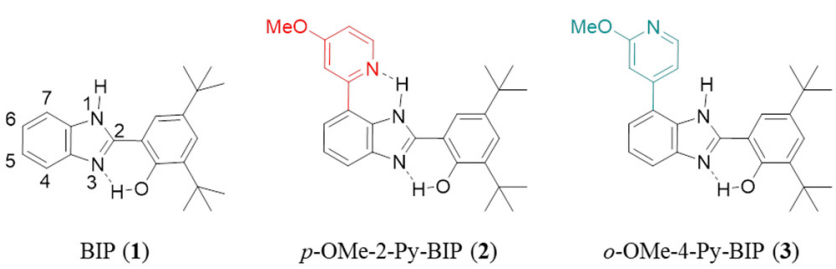

Received: September 30, 2020 
multiproton-coupled electron transfer (MPCET), where multiple proton transfers are coupled to a single redox event. Structures in which chemically reversible MPCET is observed are characterized by a continuous hydrogen-bond network and a negative $\Delta G$ for proton translocations. It is convenient to express $\Delta G$ for successive proton translocations to intermediate basic sites ending with the terminal proton acceptor (TPA) as occurring along sites having increasing $\mathrm{p} K_{\mathrm{a}}$ values. $^{21}$ For example, to accomplish an E2PT process, where two proton transfers are coupled to a single redox event, different TPAs have been evaluated, and tertiary amines $\left(-\mathrm{CH}_{2} \mathrm{NEt}_{2}\right)^{22}$ or substituted imines (Cy-imine or Ph-imine) with sufficiently high $\mathrm{p} K_{\mathrm{a}}$ 's have been proven effective. ${ }^{20,21}$ On the other hand, when the $\Delta \mathrm{p} K_{\mathrm{a}}$ between the benzimidazole and the presumptive TPA is unfavorable (i.e., the TPA is less basic than the benzimidazole), the proton translocation process is limited to one-electron, one-proton transfer (i.e., an E1PT process), and the final PCET product detected is the corresponding benzimidazolium ion. ${ }^{20}$

It also has been shown that protons can be translocated through a bridge containing two benzimidazole units to a TPA $\left(-\mathrm{CH}_{2} \mathrm{NEt}_{2}\right.$, Cy-imine, or $\mathrm{Ph}^{\mathrm{OMe}}$ imine $){ }^{23}$ enabling an E3PT process to take place. Indeed, a detailed study of E2PT- and E3PT-based systems illustrates the contribution of the electronic structure of the bridge to the negative $\Delta G$ for the MPCET process. ${ }^{23}$ Furthermore, an E4PT process (with $\mathrm{Cy}$ imine as TPA) was observed for an assembly containing a triple-benzimidazole-based bridge. ${ }^{21}$ The imines used as TPAs (Cy-imine or Ph-imine) exhibit characteristic IR features for their protonated states, which are essential for tracking the course of proton translocations and mapping the various PCET and MPCET products by using infrared spectroelectrochemistry (IRSEC). ${ }^{20,21}$

Pyridyl groups have been used as bases in mimicking the histidine residues of the $\mathrm{Y}_{\mathrm{Z}}-\mathrm{H} 190$ pair. ${ }^{24-26}$ More recently, employing density functional theory (DFT) and time-dependent density functional theory (TDDFT) calculations, a BIP derivative with a pyridyl moiety as the TPA has been proposed to undergo an excited-state PCET, and the transfer of two protons in a stepwise manner was predicted. ${ }^{27}$ Nonequilibrium first-principles molecular dynamics simulations have provided further insights into this type of concerted but asynchronous E2PT process and have identified the crucial vibrational modes for proton transfer. ${ }^{28}$ Considering that the $\mathrm{p} K_{\mathrm{a}}$ of the pyridyl group is in the same range as the benzimidazole moiety, ${ }^{29,30}$ pyridyl-BIPs are attractive candidates to evaluate whether ground-state PCET processes can indeed occur. Both the neutral and protonated forms of the pyridyl moiety in the ground state have characteristic and different IR transitions; ${ }^{31,32}$ thus, arrival of the proton in a PCET process can be detected by using a variety of techniques including IRSEC. Also, pyridines and their derivatives are robust and stable under a broad range of conditions, providing an advantage over previously studied BIP-imines, ${ }^{20,21,23}$ which are susceptible to hydrolysis. ${ }^{33}$ Furthermore, the phenoxyl radical/phenol $(\mathrm{PhO} \% \mathrm{PhOH})$ redox couple of pyridyl-substituted BIPs are within the boundaries required for water oxidation at nearneutral $\mathrm{pH}(\sim 1.00 \mathrm{~V}$ vs SCE$)$, a key feature for any application involving water splitting chemistry. This marks a significant improvement over BIP-amines, where a decrease of $\sim 300 \mathrm{mV}$ in the potential of the $\mathrm{PhO} / \mathrm{PhOH}$ redox couple was observed. $^{22}$
In this work, we describe substituted BIP systems containing pyridyl groups as TPAs (Py-BIPs), whose molecular structures are shown in Chart 1 . We have chosen to prepare and study compounds $p$-OMe-2-Py-BIP (2) and o-OMe-4-Py-BIP (3), where the only structural difference is the position of the $\mathrm{N}$ atom of the pyridyl ring. This change was made to highlight the effect on the PCET mechanism due to the disruption of the hydrogen-bond network by preventing the internal hydrogen bond between the $1 \mathrm{H}$-benzimidazole proton and the TPA.

Insights into the electrochemical behavior of these systems, including the electrostatic potentials and electric fields at the site of the transferring protons, set the stage for better understanding fundamental design principles required to construct molecular wires where protons are translocated over controlled distances via a Grotthuss-type mechanism. The ability to control the movement of electrons as well as protons is central to developing effective electrocatalysts and artificial photosynthetic assemblies.

\section{RESULTS AND DISCUSSION}

Synthesis. BIP-pyridines $p$-OMe-2-Py-BIP (2) and $o$-OMe4-Py-BIP (3) were obtained following the four steps synthetic strategy depicted in Scheme S1 (see the Supporting Information). It starts with the Miyaura borylation reaction of 4-bromobenzo[c]1,2,5-thiadiazole (Br-BTD, A) with bis(pinacolato)diboron to obtain the corresponding boronate B. ${ }^{34}$ Compound B was used as substrate for a Suzuki-Miyaura reaction with different pyridine bromides $(\mathrm{Br}-\mathrm{Py})^{35}$ to achieve the desired pyridyl-BTD derivatives ( $p$-OMe-2-Py-BTD (C) and $o$-OMe-4-Py-BTD (D), Scheme S1). Compounds $\mathbf{C}$ and D were obtained in moderate yields $(40-65 \%$ for the two steps). Sulfur extrusion of $\mathbf{C}$ and $\mathbf{D}$ employing $\mathrm{NaBH}_{4}$ as reducing agent and $\mathrm{CoCl}_{2} \cdot 6 \mathrm{H}_{2} \mathrm{O}$ as catalyst ${ }^{36,37}$ made possible the synthesis of the corresponding pyridine-benzene diamine derivatives ( $\mathbf{E}$ and $\mathbf{F})$. After work-up, the diamine was directly used in the next step due to its instability. Finally, a condensation reaction of each diamine ( $\mathbf{E}$ and $\mathbf{F}$ ) with 3,5di-tert-butyl-2-hydroxybenzaldehyde in nitrobenzene led to the desired Py-BIPs (2 and 3 ) with an overall yield for the last two steps of $\sim 50 \%$. The complete synthetic procedure and NMR characterization are provided in sections 2 and 3 of the Supporting Information.

Structural Characterization. Compounds 1-3 were studied by ${ }^{1} \mathrm{H}$ NMR to characterize the internal hydrogen bond between the $1 \mathrm{H}$-benzimidazole $(\mathrm{NH})$ and the TPA (Py) in the case of $\mathbf{2}$ as well as the hydrogen bond between the phenolic proton $\mathrm{OH}$ and the nitrogen lone pair of the benzimidazole for all three compounds. Chemical shifts of key resonances in $\mathrm{CDCl}_{3}$ are compared and summarized in Table 1 and Figure 1. The $\mathrm{OH}$ chemical shift $(\delta \mathrm{OH})$ in compounds 1-3 appears between 13 and 14 ppm, quite deshielded for a phenol $\mathrm{OH}$. This is ascribed to the strong hydrogen bond between the $\mathrm{OH}$ and the proximal $\mathrm{N}$ atom of the benzimidazole. In compound 2, the strength of the internal hydrogen bond between the $1 \mathrm{H}$-benzimidazole proton and the TPA is evidenced by analyzing both the IR NH stretching frequency (see IRSEC studies below) and the ${ }^{1} \mathrm{H}$ NMR chemical shift $(\delta \mathrm{NH})$, i.e., the signal at $12.36 \mathrm{ppm}$ (Table 1 and Figure $1 \mathrm{~B})$. This value is larger than in other BIP derivatives previously studied (BIP-Ph ${ }^{\mathrm{OMe}}$ imine, ${ }^{20} \mathrm{BIP}-\mathrm{Cy}$ imine, $^{21}$ and $\left.\mathrm{BIP}-\mathrm{CH}_{2} \mathrm{NEt}_{2}\right)$, ${ }^{22}$ where E2PT processes were demonstrated. In these earlier studies, we were able to 
Table 1. Selected ${ }^{1} \mathrm{H}$ NMR Chemical Shifts of Compounds 1-3

\begin{tabular}{|c|c|c|}
\hline \multirow[b]{2}{*}{ compound } & \multicolumn{2}{|c|}{ chemical shift $(\mathrm{ppm})^{a}$} \\
\hline & $\delta \mathrm{NH}$ & $\delta \mathrm{OH}$ \\
\hline $1^{b}$ & 9.34 & 13.46 \\
\hline 2 & 12.36 & 13.48 \\
\hline 3 & $9.59(9.48)^{c}$ & 13.14 \\
\hline 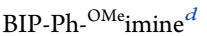 & 11.84 & 13.30 \\
\hline BIP-Cy-imine ${ }^{e}$ & 11.87 & 13.30 \\
\hline $\mathrm{BIP}-\mathrm{CH}_{2} \mathrm{NEt}_{2}{ }^{f}$ & 11.17 & 13.45 \\
\hline
\end{tabular}

${ }^{a}$ All data were recorded in $\mathrm{CDCl}_{3} .{ }^{b}$ Data from ref 22. ${ }^{c}$ In parentheses $\delta$ (ppm) of the minor isomer. ${ }^{d}$ Data from ref $20 .{ }^{e}$ Data from ref 21. $f_{\text {Data from ref } 22 .}$

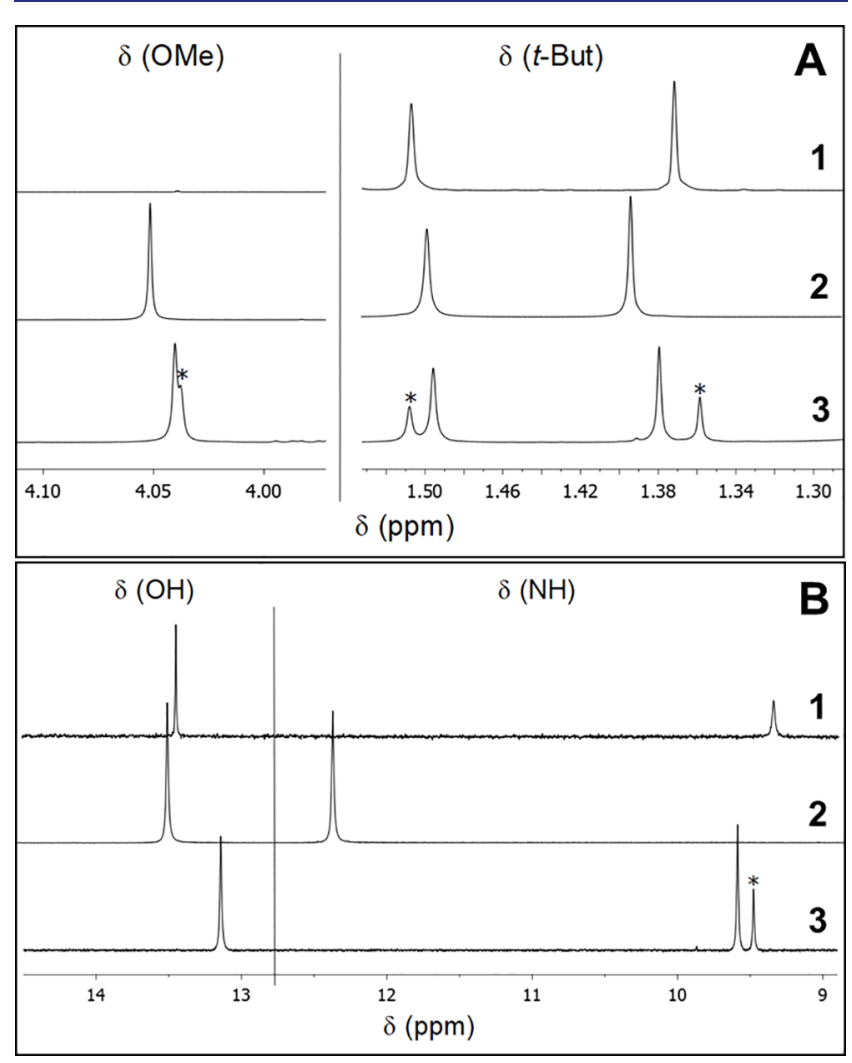

Figure 1. ${ }^{1} \mathrm{H}$ NMR spectra of compounds $1-3$ recorded in $\mathrm{CDCl}_{3}$. (A) Resonances for the OMe and tert-butyl groups (the vertical line separates both regions). (B) Resonances for the $\mathrm{OH}$ and $\mathrm{NH}$ groups (the vertical line separates both regions). (*) Highlights the minor isomer present in solution for compound 3 . The $\mathrm{OH}$ signal for the minor isomer is not apparent due to the broadness of this signal.

correlate the strength of such a hydrogen bond with the $\delta \mathrm{NH}$; the stronger the hydrogen bond, the larger $\delta \mathrm{NH}$. Thus, in the case of 2 we have a stronger hydrogen bond between the $1 \mathrm{H}$ benzimidazole proton and the TPA than in any of the examples previously examined. The interruption of the hydrogen-bond network in compound 3 results in a drastic change in the benzimidazole $\mathrm{NH}$ resonance $(\delta \mathrm{NH}$ at $9.59 \mathrm{ppm}$, Table 1 and Figure $1 \mathrm{~B})$. For this compound, the $\delta \mathrm{NH}$ is close to that observed for $1(9.34 \mathrm{ppm})^{22}$ where the absence of a TPA precludes the formation of the alluded hydrogen bond.

Substitution at the 7-position of the benzimidazole moiety of $\mathbf{1}$, as in $\mathbf{2}$ and $\mathbf{3}$, results in the possibility of isomeric forms arising from 1,3-tautomerism of the imidazole and rotation around the bond between the benzimidazole and phenolic moieties to yield BIPs with substitution at the 4-position (Figure S9). ${ }^{38,39}$ Only one of the isomers has the internal hydrogen-bond network required to undergo a chemically reversible E2PT process. Compound 2 exhibits two hydrogenbond interactions, and only one isomer is observed by ${ }^{1} \mathrm{H}$ NMR (Figure 1). This observation is in full agreement with DFT calculations where both structures associated with the isomeric forms were optimized for compound 2. The theoretical results indicate that the structure with two hydrogen bonds predominates $(\leq 99.9 \%)$ under equilibrium at $298 \mathrm{~K}$ (Figure S9 and Table S1).

On the other hand, the interruption of the hydrogen-bond network in compound 3 results in a mixture of isomers in $\mathrm{CDCl}_{3}$, as shown in its ${ }^{1} \mathrm{H}$ NMR spectrum (Figure 1). The presence of isomers was also verified by their ${ }^{1} \mathrm{H}$ NMR spectra in other solvents. In the case of compound 3, isomeric ratios of 1:0.48 in $\mathrm{CDCl}_{3}$ and 1:0.17 in acetone- $d_{6}$ were observed (Figure S10). DFT calculations for the isomeric forms of compound 3 at equilibrium $(298 \mathrm{~K})$ show a small energy difference between the isomeric forms $(<1 \mathrm{kcal} / \mathrm{mol}$, Figure $\mathrm{S} 9$ and Table S1). These theoretical results agree with the experimental ${ }^{1} \mathrm{H}$ NMR data.

Electrochemical Studies. Figure 2 shows the cyclic voltammograms (CVs) of compounds 1-3, and Table 2 summarizes the experimental and calculated redox potentials along with data related to the chemical and electrochemical reversibility of the $\mathrm{PhO} / \mathrm{PhOH}$ redox couples. The redox potentials were computed by using $\mathbf{1}$ as the reference. Redox potentials corresponding to 0,1 , and 2 proton transfers (e.g., E0PT, E1PT, and E2PT) for 2 and 3 were computed and are given in Table S3. In Table 2, the redox potential for $\mathbf{2}$ corresponds to an E2PT mechanism, whereas the redox potential for 3 corresponds to an E1PT mechanism as indicated by the analysis below. Additional computational details are given in the Supporting Information (section S8).

Compound 1 exhibits a one-electron electrochemical redox process (Figure 2A), and the experimental midpoint potential $\left(E_{1 / 2}\right.$, taken as the average of the anodic and cathodic peaks) of the $\mathrm{PhO} \% / \mathrm{PhOH}$ redox couple is $0.95 \mathrm{~V}$ vs SCE. The peak-topeak separation $\left(\Delta E_{\mathrm{p}}\right)$ of $70 \mathrm{mV}$ denotes quasi-reversible electrochemistry, while the chemical reversibility is evidenced by the high value of the cathodic to anodic peak currents ratio $\left(i_{\mathrm{c}} / i_{\mathrm{a}}=0.95\right.$, Table 2$)$. CVs at different scan rates were also recorded $\left(100-1000 \mathrm{mV} \mathrm{s}^{-1}\right)$ and were digitally simulated. As shown in Figure S16, there is a good match between the experimental and simulated CVs, and the $i_{\mathrm{c}} / i_{\mathrm{a}}$ ratio values are around one for all scan rates, confirming the quasi-reversible electrochemical assignment and the chemical reversibility of the system. It was previously demonstrated that the $E_{1 / 2}$ of this redox couple and its chemical and electrochemical reversibility are associated with a concerted transfer of the phenolic proton to the benzimidazole, forming an E1PT product (benzimidazolium ion). ${ }^{18,22}$

Compound 2 displays a quasi-reversible one-electron redox couple as well (Figure 2B), with an $E_{1 / 2}$ of $0.85 \mathrm{~V}$ vs SCE, a $\Delta E_{\mathrm{p}}$ of $70 \mathrm{mV}$, and an $i_{\mathrm{c}} / i_{\mathrm{a}}$ ratio of 0.90 at a scan rate of 100 $\mathrm{mV} \mathrm{s}^{-1}$ (Table 2). CVs at different scan rates were also recorded and digitally simulated for $\mathbf{2}$ (see Figure S17) considering a quasi-reversible electrochemical system. The concordance between the experimental and simulated CVs together with $i_{\mathrm{c}} / i_{\mathrm{a}}$ ratio values close to one for all scan rates corroborates that $\mathbf{2}$ is also chemically reversible. Similar behavior was previously observed in related BIP derivatives 

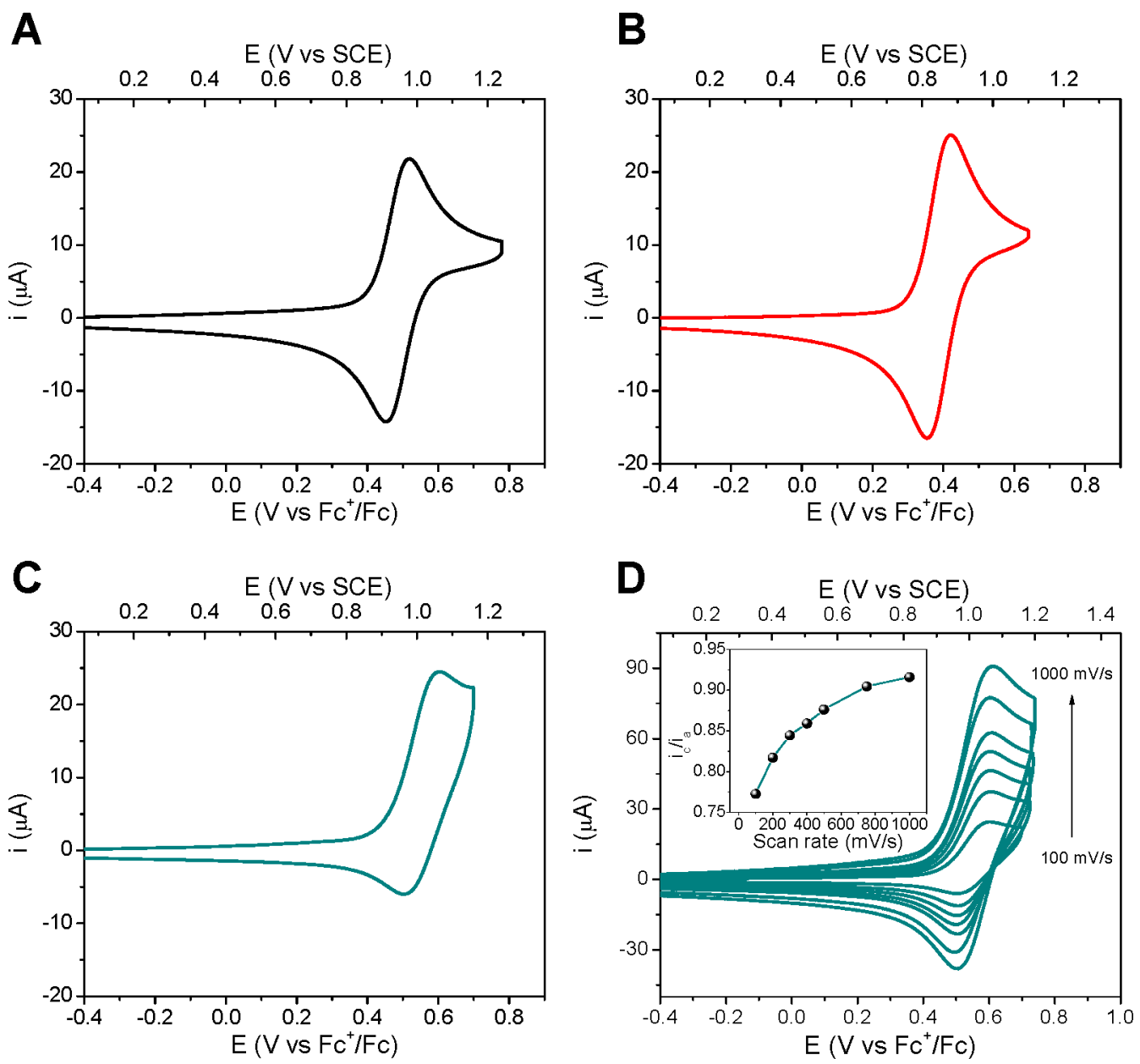

Figure 2. (A-C) Cyclic voltammograms of 1-3, respectively, collected at $100 \mathrm{mV} \mathrm{s}^{-1}$. (D) Cyclic voltammograms of 3 collected at different scan rates $\left(100,200,300,400,500,750\right.$, and $\left.1000 \mathrm{mV} \mathrm{s}^{-1}\right)$. The inset shows the cathodic to anodic peak intensity ratios $\left(i_{\mathrm{c}} / i_{\mathrm{a}}\right)$ as a function of the scan rate. Experimental conditions: $1 \mathrm{mM}$ of the indicated compounds, $0.1 \mathrm{M} \mathrm{TBAPF}_{6}$ supporting electrolyte in dry DCM.

Table 2. Electrochemical Data of Compounds 1-3 in DCM

\begin{tabular}{|c|c|c|c|c|c|c|c|}
\hline compd & $\begin{array}{c}E p_{\mathrm{a}} \\
(\mathrm{V} \text { vs } \\
\left.\mathrm{Fc}^{+} / \mathrm{Fc}\right)\end{array}$ & $\begin{array}{c}E p_{\mathrm{c}} \\
(\mathrm{V} \mathrm{vs} \\
\left.\mathrm{Fc}^{+} / \mathrm{Fc}\right)\end{array}$ & $\begin{array}{c}E_{1 / 2} \\
(\mathrm{~V} / \mathrm{vs} \\
\left.\mathrm{Fc}^{+} / \mathrm{Fc}\right)\end{array}$ & $\begin{array}{l}E_{1 / 2}{ }^{a} \\
(\mathrm{~V} \text { vs } \\
\text { SCE) }\end{array}$ & $\begin{array}{c}\text { calcd } \\
E_{1 / 2}(V \\
\text { vs SCE })\end{array}$ & $\begin{array}{c}\Delta E \\
(\mathrm{mV})\end{array}$ & $i_{c} / i_{a}^{b}$ \\
\hline 1 & 0.52 & 0.45 & 0.49 & 0.95 & $0.95^{c}$ & 70 & 0.95 \\
\hline 2 & 0.42 & 0.35 & 0.39 & 0.85 & $0.72^{d}$ & 70 & 0.90 \\
\hline 3 & 0.60 & 0.50 & $0.55^{e}$ & $1.01^{e}$ & $1.04^{f}$ & 100 & 0.77 \\
\hline
\end{tabular}

${ }^{a_{T}}$ The potential of the silver wire pseudoreference electrode was determined by using the ferrocenium/ferrocene redox couple as an internal standard and adjusting it to the saturated calomel electrode (SCE) scale (with $E_{1 / 2}$ taken to be $0.46 \mathrm{~V}$ vs SCE in DCM). ${ }^{45}$ ${ }^{b}$ Cathodic-to-anodic peak intensity ratios $\left(i_{c} / i_{\mathrm{a}}\right)$ measured at a scan rate of $100 \mathrm{mV} \mathrm{s}^{-1}$. ${ }^{c}$ Reference potential for the calculated $E_{1 / 2}$ for all the compounds in this table; agrees by construction. ${ }^{d}$ The redox potential for compound 2 was computed for the E2PT process, which is thermodynamically favorable. ${ }^{e} E_{1 / 2}$ measured at a scan rate of 1000

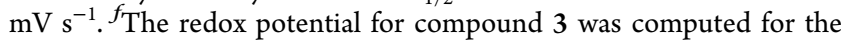
$\mathrm{E} 1 \mathrm{PT}$ process based on experimental evidence. The E2PT process is slightly more thermodynamically favorable, with an $E_{1 / 2}$ of $0.98 \mathrm{~V}$ vs SCE, but is thought to be inaccessible at high scan rates because the hydrogen-bond network is disrupted.

bearing different TPAs. ${ }^{20-22}$ On the other hand, the $\mathrm{PhO} \%$ $\mathrm{PhOH}$ redox couple observed in the $\mathrm{CV}$ of 3 (Figure 2C) presents different electrochemical and chemical behavior in comparison to those observed for $\mathbf{1}$ and $\mathbf{2}$, collected at the same scan rate $\left(100 \mathrm{mV} \mathrm{s}^{-1}\right)$. The $\Delta E_{\mathrm{p}}$ is $100 \mathrm{mV}$, and the $i_{\mathrm{c}} / i_{\mathrm{a}}$ ratio is 0.77 (Table 2). Nevertheless, the CVs of 3 collected at increasingly faster scan rates shows that $i_{\mathrm{c}} / i_{\mathrm{a}}$ increases as a function of the scan rate, reaching $>0.9$ at $1000 \mathrm{mV} \mathrm{s}^{-1}$ (Figure 2D, inset).

The differences in electrochemical behavior of compounds 1-3 must be related to the structure of theses constructs. In 3 there is a change in the position of the $\mathrm{N}$ atom in the pyridyl ring, relative to isomer 2 , breaking the internal hydrogen-bond network. The reversibility profile for 3 is consistent with an EC mechanism, $^{40}$ in which the oxidation of the phenol (an electrochemical E step that is concerted with a proton transfer to form an E1PT product) is followed by an irreversible chemical reaction (a $\mathrm{C}$ step). However, at fast scan rates, the rate of the electrochemical reduction can outcompete the irreversible chemical step, resulting in a more chemically reversible redox wave. To confirm the proposed EC mechanism, experimental CVs of 3 at several scan rates were digitally simulated by using the above-mentioned mechanism (Figure S18). The experimental and simulated CVs obtained are very similar, which supports the assumption of an EC mechanism in 3. Further details and evidence of this proposed mechanism are addressed below with the IRSEC of these compounds.

The $E_{1 / 2}$ values show that the phenol is easier to oxidize in these compounds following the sequence 2,1 , and 3, with 2 being the easiest to oxidize. The drop in $E_{1 / 2}$ of $\mathbf{2}$, relative to 1 

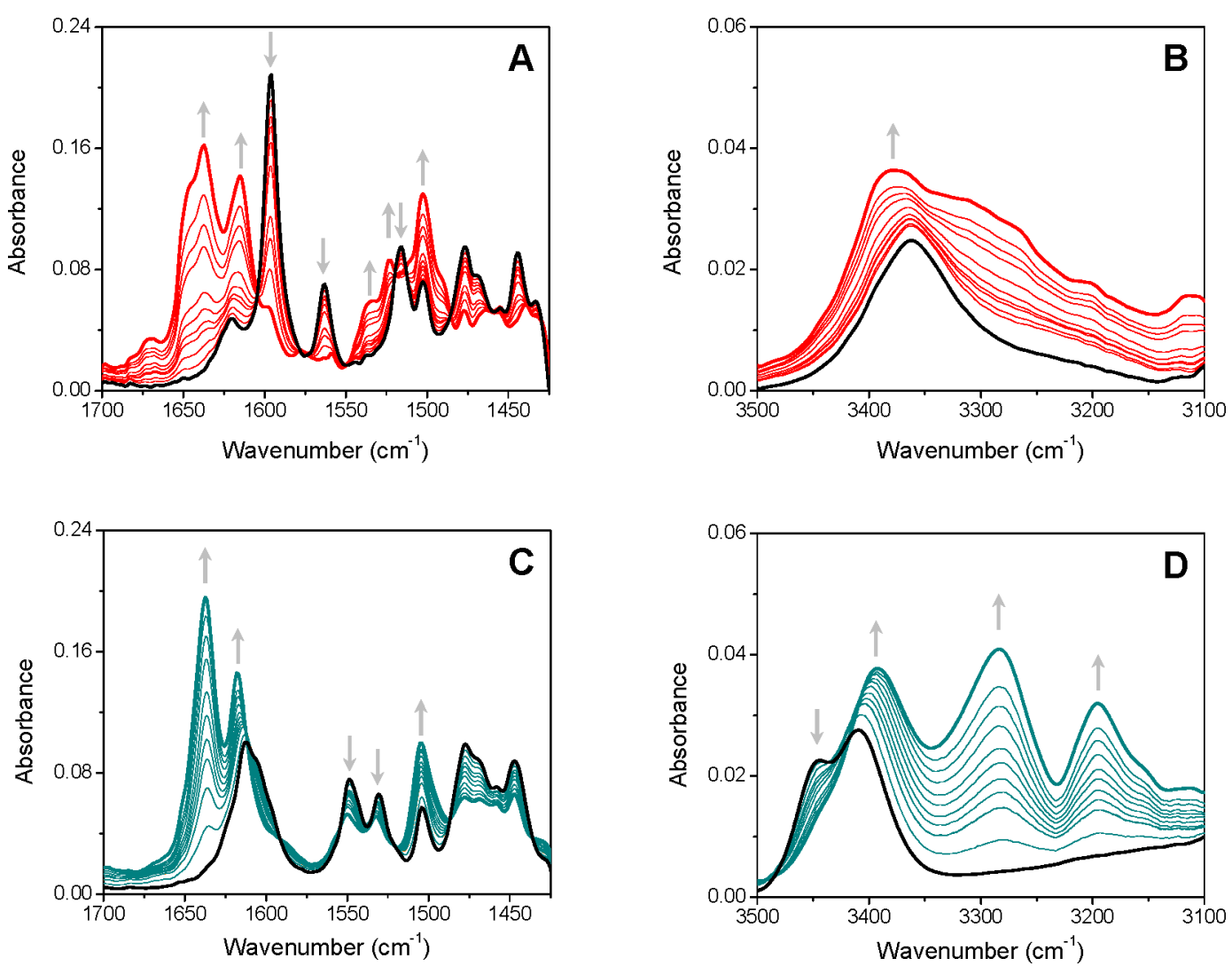

Figure 3. (A, C) IRSEC spectra of 2 and 3, respectively, recorded under electro-oxidative conditions in the middle frequency region (1700-1425 $\left.\mathrm{cm}^{-1}\right)$. (B, D) IRSEC spectra of 2 and 3, respectively, with the same conditions in the higher frequency region $\left(3500-3100 \mathrm{~cm}^{-1}\right)$. Solvent: dry $\mathrm{DCM}, 0.1 \mathrm{M} \mathrm{TBAPF}_{6}$. Characteristic bands displaying changes under polarization are indicated with upward and downward gray arrows.

and 3, is ascribed to a MPCET process leading to an E2PT product. Theoretical calculations address the experimental evidence and reinforce the assignment of the E2PT product as the thermodynamically most stable (see Table S3). The disruption of the hydrogen-bond network in 3 causes an anodic shift of the $E_{1 / 2}$ compared to its isomer 2 , and the resulting $E_{1 / 2}$ measured at high scan rates is close to that observed for 1, where an E1PT process was previously verified $(\sim 1.00 \mathrm{~V}$ vs SCE).

The reversibility of the $\mathrm{PhO} / \mathrm{PhOH}$ redox couple is a key factor to understanding the PCET and MPCET processes involved in these BIP compounds. As mentioned above, compounds 1 and $\mathbf{2}$ show a relatively high degree of chemical reversibility $\left(i_{c} / i_{a}\right.$ close to one for all scan rates), which is attributed to the phenolic proton translocating between the atoms involved in its hydrogen-bond network during the interconversion between the reduced and the oxidized species. ${ }^{41}$ This phenomenon has also appeared in previously reported analogous BIP derivatives where the proton translocation could be extended even up to $\sim 16 \AA$ without affecting the chemical or the electrochemical reversibility of the $\mathrm{PhO} \%$ $\mathrm{PhOH}$ redox couple. ${ }^{21,23}$ In contrast, compound 3 is chemically irreversible at low scan rates, which is frequently observed in electrochemical oxidations of phenols in the absence of a proximal basic site to serve as a proton acceptor. ${ }^{42,43}$ The change in the chemical reversibility arising from breaking a hydrogen-bond network is similar to that observed in previously studied systems. ${ }^{44}$

Infrared Spectroelectrochemical Studies. Figure 3 shows the IRSEC spectra of compounds 2 and 3 . In the
1700-1425 $\mathrm{cm}^{-1}$ frequency region of the spectrum of 2 (Figure 3A), we observed that bands located at 1564 and 1596 $\mathrm{cm}^{-1}$, attributed to ring stretching modes of the pyridyl group, ${ }^{46-48}$ gradually decreased, and three new bands of medium to high intensity at 1534,1616 , and $1638 \mathrm{~cm}^{-1}$ appeared upon electrochemical oxidation. These latter bands are assigned to vibrational modes of the protonated pyridyl group. Similar bands are observed when a solution of 2-bromo4-methoxypyridine (a model compound, precursor of C, Scheme S1) was titrated with TFA (Figure S12). Previous FTIR studies of pyridinium salts ${ }^{31,32,49,50}$ in the solid state and in solution showed that this set of bands arises from motions unlikely to be affected by peripheral interactions, and they are mostly due to vibrations in the pyridyl ring affected by protonation of the pyridyl nitrogen. The formation of the oxidized species in $\mathbf{2}$ following MPCET can also be monitored by the changes in the absorbance band at $\sim 1516 \mathrm{~cm}^{-1}$ associated with the benzimidazole $\mathrm{NH}$ in-plane bending mode. $^{22}$ The frequency of this band denotes the presence of a strong internal hydrogen bond between the $\mathrm{NH}$ of the benzimidazole and the pyridyl nitrogen; it is located at a lower frequency as compared to the equivalent band observed for 1 $\left(\sim 1526 \mathrm{~cm}^{-1}\right)$ and the isomer 3 (vide infra). Following electrochemical oxidation of 2 , this band decreased, and a new band at $\sim 1522 \mathrm{~cm}^{-1}$, assigned to the $\mathrm{NH}$ in-plane bending mode of the proximal $\mathrm{NH}$ of the benzimidazole, appeared (Figure $3 \mathrm{~A}){ }^{22}$

The benzimidazole $\mathrm{NH}$ stretching mode frequency $\left(\nu_{\mathrm{NH}}\right)$ in the $3500-3100 \mathrm{~cm}^{-1}$ region (Figure $3 \mathrm{~B}$ ) is indicative of a relatively strong hydrogen bond between the pyridyl nitrogen 

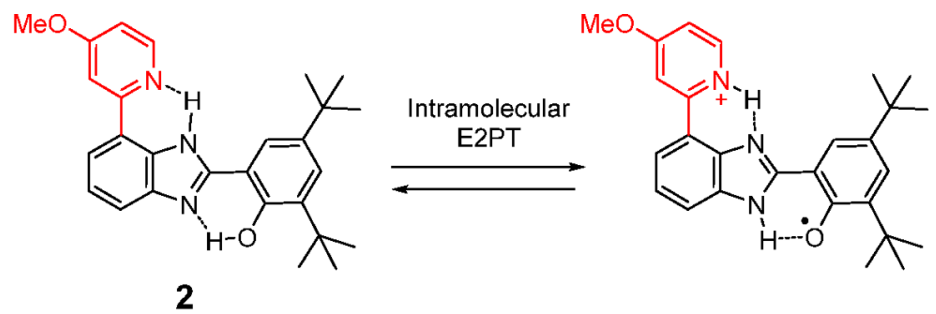

2
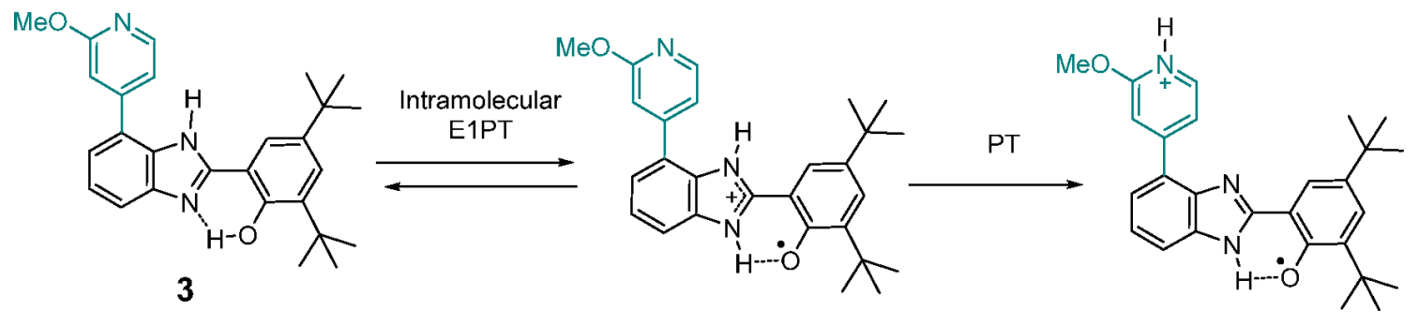

Figure 4. Proposed PCET mechanisms involved upon phenol oxidation of compounds 2 and 3. Disruption of the hydrogen-bond network in 3 would lead to a hypothetical E1PT step followed by a PT process.

and the benzimidazole $\mathrm{NH}$ of 2 . In the neutral species (black trace), the $\nu_{\mathrm{NH}}$ was observed at $3360 \mathrm{~cm}^{-1}$, significantly lower than the $\nu_{\mathrm{NH}}$ for $1\left(3414 \mathrm{~cm}^{-1}\right) .^{22}$ A gradual shift of the $\nu_{\mathrm{NH}}$ to higher frequencies, combined with an increase in the intensity and broadness of the band at lower frequencies, was observed upon electrochemical oxidation. The absence of a band associated with the presence of a benzimidazolium ion (typically observed at $\sim 3320 \mathrm{~cm}^{-1}$ ) 22 and the similar position of the $\nu_{\mathrm{NH}}$ band before and after oxidation of the phenol imply that the hydrogen-bonded network persists in 2 . In fact, this well-defined network is a requirement for reversing the position of both protons upon reduction of the phenoxyl radical and re-establishing the neutral species as shown in Figure S14. In summary, the observations discussed above, together with the changes displayed in the IRSEC spectra collected in the $1700-1425 \mathrm{~cm}^{-1}$ region, and the absence of a band at $\sim 1556 \mathrm{~cm}^{-1}$ (indicative of the $\mathrm{NH}$ in-plane bending vibration mode of the benzimidazolium ion in an E1PT product), ${ }^{22}$ confirm the translocation of both protons and formation of a chemically stable E2PT product (Figure 4). The close agreement between the experimental IRSEC of $\mathbf{2}$ and DFT normal-mode analysis supports the assignments of the observed bands (Figure S19 and Table S4).

The IRSEC spectra of 3 collected in the $1700-1425 \mathrm{~cm}^{-1}$ (Figure 3C) and 3500-3100 $\mathrm{cm}^{-1}$ (Figure 3D) regions do not show the characteristic bands at $\sim 1556$ and $\sim 3320 \mathrm{~cm}^{-1}$, respectively, indicating that the corresponding benzimidazolium ion is not detected under the conditions of the experiment. In the neutral species (black trace), the $\mathrm{NH}$ inplane bending mode is located at a higher frequency relative to $2\left(\sim 1530 \mathrm{~cm}^{-1}\right.$ for $3 \mathrm{vs} \sim 1516 \mathrm{~cm}^{-1}$ for 2$)$, in agreement with the absence of the internal hydrogen bond with the nitrogen lone pair of the pyridine, and this band only showed a minor change in its intensity upon polarization. In addition, two new intense bands growing in at 1617 and $1637 \mathrm{~cm}^{-1}$, typical of a protonated pyridyl species, were recorded (Figure 3C). These results suggest that on the time scale of the FTIR experiments the pyridyl TPA becomes protonated, which is consistent with the previously proposed EC mechanism for proton translocation in 3. In this mechanism, the E step is concerted with proton transfer to form an intermediate benzimidazolium ion (which is not detected on the time scale of the bulk electrolysis) followed by a chemical step involving a second proton transfer from a benzimidazolium ion to form a protonated pyridyl moiety and the formation of an E2PT product. This is the C step, labeled PT in Figure 4, which is likely an intermolecular process.

A key difference between the spectral features associated with 3 and 2 is noticeable in the $3500-3100 \mathrm{~cm}^{-1}$ region. As can be seen in Figure $3 \mathrm{D}$, the $\nu_{\mathrm{NH}}$ associated with the neutral form of 3 (black trace) displays two components with maxima at 3410 and $3445 \mathrm{~cm}^{-1}$ that can be assigned to the presence of two isomeric forms of 3 in the sample (Figure S9 and Table $\mathrm{S} 1$ ). In the case of the neutral form of $\mathbf{2}$ only a single $\nu_{\mathrm{NH}}$ band is observed (black line in Figure $3 \mathrm{~B}$ ), indicating the dominance of a single isomer for this molecule, featuring an extended hydrogen-bond array. This agrees with NMR observations (Figure 1 and Table 1) and theoretical studies (Table S1). The $\nu_{\mathrm{NH}}$ for 3 at $3410 \mathrm{~cm}^{-1}$ behaves like a "free" $\nu_{\mathrm{NH}}$ (nonhydrogen bonded), comparable to the $\nu_{\mathrm{NH}}$ in compound $\mathbf{1}$ $\left(3414 \mathrm{~cm}^{-1}\right)^{22}$ because of the disruption in the hydrogen bond network. As we observe in Figure 3D, the band at $3445 \mathrm{~cm}^{-1}$, corresponding to the $\nu_{\mathrm{NH}}$ of one of the isomers of 3 (Figure S9), disappears, and three well-defined bands at 3392, 3283, and $3195 \mathrm{~cm}^{-1}$ appear upon phenol oxidation. The last two bands are associated with the protonated form of the pyridyl ring $\left(\nu_{\mathrm{PyNH}}{ }^{+}\right.$, similar bands are observed when titrating 4bromo-2-methoxypyridine with TFA, Figure S13). The complex nature of the $\nu_{\mathrm{PyNH}}{ }^{+}$in pyridinium salts has been explained by the effect of Fermi resonance perturbation and the type and field strength of the counterion in its proximity, among other factors, and some of these $\nu_{\mathrm{PyNH}}{ }^{+}$are not single bands and can be described as multicomponent bands. ${ }^{31,32,49,50}$ Many pyridinium salts have been explained as interionic hydrogen-bonded complexes $\left(\mathrm{PyNH}^{+}---\mathrm{A}^{-}\right.$, where $\mathrm{A}$ is the anion in solution). ${ }^{15}$

The difference between the two E2PT products obtained on the time scale of IRSEC experiments in $\mathbf{3}$ vs one E2PT product for $\mathbf{2}$ is due to the presence of the intramolecular hydrogen bond involving the protonated pyridyl group in 2 . As remarked before, the hydrogen-bond network in 2 persists upon phenol oxidation, and the protonated form of the pyridyl group remains hydrogen bonded with the benzimidazole nitrogen, minimizing the surrounding interactions (e.g., with the 
A

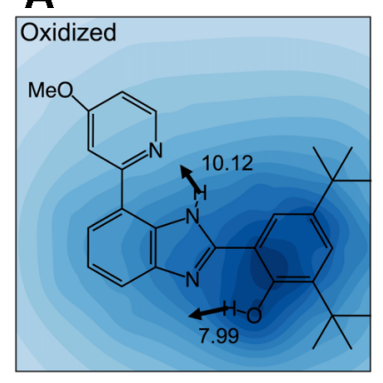

B

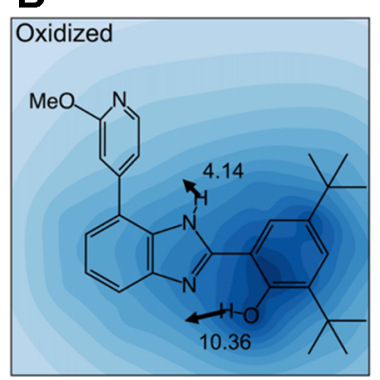

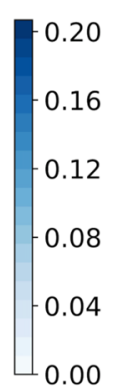
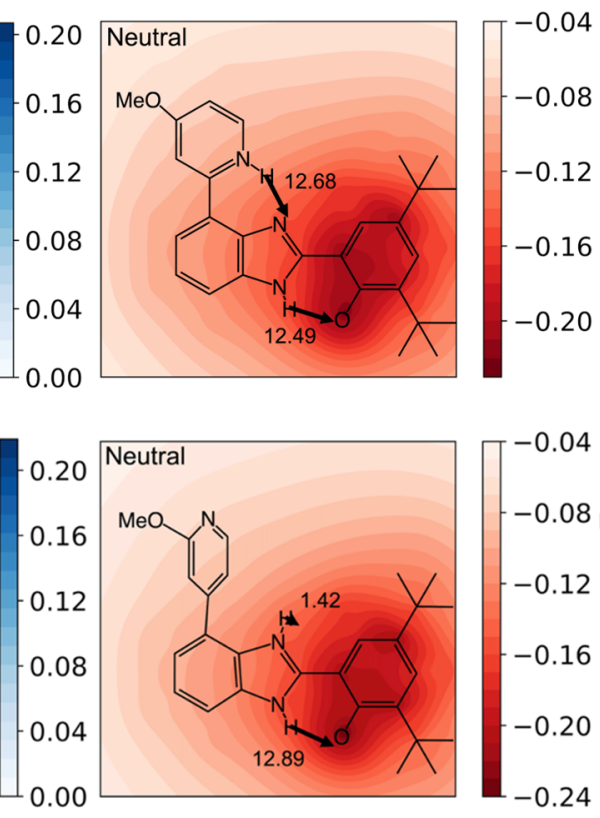

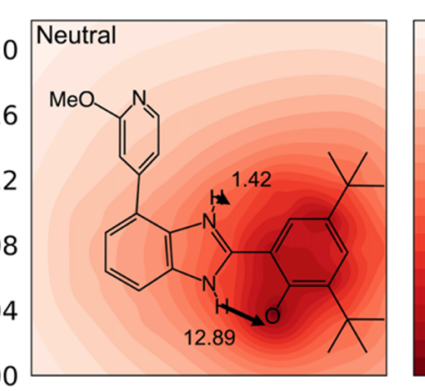

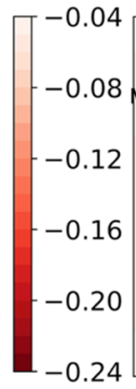

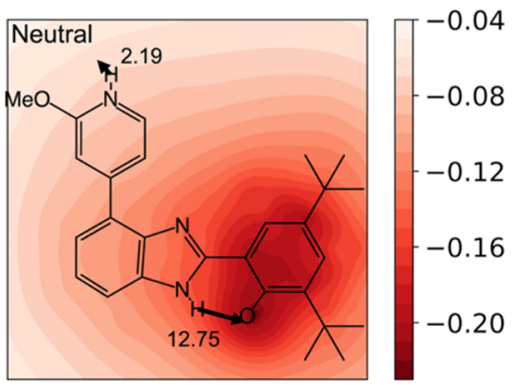

Figure 5. Contour plots of the electrostatic potential differences (au) in the plane of the aromatic system with the black arrows and numbers indicating the direction and magnitude $(\mathrm{V} / \mathrm{nm})$ of the electric field at the transferring protons. (A) Compound 2 in the oxidized state ( $\mathrm{e}^{-}$ removed) at the neutral reactant geometry (left) and the neutral state ( $\mathrm{e}^{-}$added) at the oxidized E2PT product geometry (right). (B) Compound 3 in the oxidized state ( $\mathrm{e}^{-}$removed) at the neutral reactant geometry (left) and neutral state $\left(\mathrm{e}^{-}\right.$added) at the oxidized E1PT product (middle) and E2PT product (right) geometry. The blue (red) plots correspond to the difference between the electrostatic potentials of the oxidized (neutral) and neutral (oxidized) states. The direction of the arrows is along the steepest field gradient.

supporting electrolyte). Indeed, the maintenance of this network upon phenol oxidation and proton translocation is manifested in the chemical reversibility of the $\mathrm{PhO} / \mathrm{PhOH}$ redox couple in $\mathbf{2}$ (Table 2) and corroborated by the recovery of the starting spectrum upon reversal of the polarization in the IRSEC experiment (Figure S14). In contrast, the protonated pyridyl species generated in 3 by PT following the initial formation of the E1PT product (Figure 4) is "exposed" to the surrounding environment and would likely interact with, for example, the anion $\mathrm{PF}_{6}{ }^{-}$of the supporting electrolyte. This interaction could be responsible for the complexity (two major E2PT products) observed in the $\nu_{\mathrm{PyNH}}{ }^{+}$band. ${ }^{32,50}$ Following the experiments performed under oxidative polarization, the application of a reductive bias potential shows that the spectral features associated with the neutral species for 3 can be restored, indicating that the translocation of both protons is reversible on the relatively longer time scale of the IRSEC experiments as compared to the cyclic voltammetry experiments (Figure S15).

Mechanistic Understanding from Combined Experimental and Theoretical Data. Figure 4 summarizes the experimental and theoretical observations and describes the proposed PCET processes for $\mathbf{2}$ and 3, based on several factors. First, interruption of the hydrogen-bond network in 3 results in the formation of isomeric structures in solution (Figure 1, Table 1, Figure S9, and Table S1). Our interpretation does not depend in detail on these structures; it depends only on the point that in those isomers of 3 the hydrogen-bond network connecting the phenolic proton with the pyridyl nitrogen is interrupted between the benzimidazole and the pyridyl group. Second, $E_{1 / 2}$ for 3 can only be evaluated under the chemically reversible conditions observed at the highest sweep rates of the cyclic voltammetry; its value is characteristic of an E1PT process (Figure 2C and Table 2).
Third, in both 2 and 3 the IRSEC indicates that the pyridinium cation is reversibly formed (Figure 3 and Figures S14 and S15). Unfortunately, the IRSEC measurements require the system to be in near electrochemical steady-state conditions in which the redox reaction and diffusion compensate each other under the constant applied potential of this experiment, whereas $E_{1 / 2}$ measurements require, in the case of 3 , rapid sweep rates. In other words, using IRSEC, it is not possible to record the spectra of the intermediate E1PT product that is associated with the $E_{1 / 2}$ measured for 3 when using the rapid electrochemical sweep rates required for chemical reversibility.

Therefore, the conclusion that at fast sweep rates 3 undergoes only an E1PT process is based solely on the $E_{1 / 2}$ value and not on the observation of a benzimidazolium ion in the IRSEC. It is clear that $\mathbf{3}$ has a different reversibility profile from 2 and from previous examples ranging up to E4PT products. $^{21}$

The contrast in behavior between 2 and 3 is consistent with the mechanism shown in Figure 4, where upon oxidation of $\mathbf{2}$ an overall reversible (chemically and spectroscopically as determined by IRSEC) E2PT process is observed. Upon oxidation of 3 , an overall chemically irreversible PCET process is proposed where an intramolecular E1PT step is followed by a separate PT step, which most likely involves a nonconcerted two-step process. Alternatively, when the time scale of the cyclic voltammetry experiment is short (i.e., at high scan rates), only the E1PT step occurs, and the construct features chemical reversibility but does not involve the translocation of two protons; that is, an overall E2PT process does not take place.

Further insight into the remarkably different electrochemical behavior of 2 and 3 leading to the scheme proposed in Figure 4 can be provided by computing the electrostatic forces that would act on the protons at their original positions upon electron transfer to or from the electrode. This modeling 
highlights the physical basis for the concerted mechanism, namely, the avoidance of potential high-energy intermediates. Figure 5 illustrates that these electrostatic properties are qualitatively different for 2 and 3. Upon oxidation of 2 (left panel of Figure 5A), the electrostatic potential at the phenol becomes more positive, and the electric field at the two transferring protons facilitates forward proton transfer. Similarly, upon reduction of the E2PT product of 2 (right panel of Figure 5A), the electrostatic potential at the phenoxyl radical becomes more negative, and the electric fields at the two transferring protons facilitate reverse proton transfer. The magnitudes of the electric fields for both protons in the forward and reverse direction are similar. In contrast, upon oxidation of 3 (left panel of Figure 5B), the electrostatic potential at the phenol becomes more positive, and the electric field at the phenol proton facilitates forward proton transfer, but the field at the $\mathrm{NH}$ proton of the benzimidazole is significantly smaller. Moreover, upon reduction of the E1PT and E2PT products of 3 (middle and right panels of Figure $5 B)$, the electrostatic potential at the phenoxyl radical becomes more negative; the electric field at the proton pointing toward the phenoxyl radical facilitates reverse proton transfer, but the electric field at the other proton (distal $\mathrm{NH}$ of the benzimidazolium ion in the E1PT product and $\mathrm{NH}$ of the pyridinium ion in the E2PT product) is significantly smaller and is not optimally directed.

These calculations support the hypothesis that the electric fields associated with an intact hydrogen-bond network facilitate proton transfer from the phenol through the benzimidazole to the pyridine in 2 . During the oxidation of 2 to $2^{\bullet+}$, these electric fields couple the phenol via the benzimidazole to the pyridyl-based TPA so that oxidation is coupled to double proton transfer and occurs $100 \mathrm{mV}$ lower than in the case of $\mathbf{1}$, where the less basic benzimidazole is the TPA. During the reduction of $\mathbf{2}^{\bullet+}$, the intact hydrogen-bond network and associated electric fields couple the proton on the protonated pyridyl-based TPA via the benzimidazole to the phenol. Therefore, reduction is coupled to reverse double proton transfer and occurs at a potential commensurate with the potential at which the phenol was oxidized $(\sim 0.85 \mathrm{~V}$ vs $\mathrm{SCE})$. Conversely, in 3 the hydrogen-bond network is interrupted because there is no hydrogen bond between the benzimidazole and the pyridyl-based TPA. The only basic site hydrogen bonded to the phenol is the benzimidazole, and the pyridyl-based TPA is not close enough to accept a proton from the benzimidazolium ion via an intramolecular process. Therefore, oxidation of 3 to $3^{\bullet+}$ leads to transfer of the phenolic proton to the benzimidazole and yields either the reversible $E_{1 / 2}$ of an E1PT process $(1.01 \mathrm{~V}$ vs SCE) at high scan rates, or at low scan rates, to a chemically irreversible redox couple where the concept of $E_{1 / 2}$ does not apply. To observe the reversible E1PT process of $3^{\bullet+}$, a high scan rate is required so that the reduction occurs before the benzimidazolium can deprotonate to a base. In contrast to restoration by IRSEC of the oxidized species described above, attempting to reverse the system in 3 after the PT step by a cathodic scan of the $\mathrm{CV}$ is not productive, possibly because the only proton available for the necessary intramolecular PCET process is the covalently bonded one on the benzimidazole, and its $\mathrm{p} K_{\mathrm{a}}$ is extremely high. ${ }^{51}$

\section{CONCLUSION}

In summary, the bioinspired pyridyl-substituted BIP isomers 2 and 3 illustrate the essential role of an intact hydrogen-bond network in controlling proton activity and overall chemical reversibility during MPCET. Because the $\pi$-electronic structure supporting the hydrogen-bond network is essentially the same in $\mathbf{2}$ and $\mathbf{3}$, the different electrochemical behavior of $\mathbf{2}$ and 3 must be due to the different connectivity of the hydrogen bonds and associated electric fields. On the basis of the quasireversible electrochemistry of 1,2 , and $3\left(\mathrm{CV}\right.$ at $\left.1000 \mathrm{mV} \mathrm{s}^{-1}\right)$ and our interpretations, we conclude that the basicities of proton acceptors downstream of an interruption in an intact hydrogen-bond network have little effect on the redox potential of the phenol. This suggests that the thermodynamic coupling provided by an intact hydrogen-bond network is important in bioenergetics, where the redox process associated with PCET-based proton transport responds to the transmembrane proton-motive force and adjusts appropriately. Indeed, reversibility in PCET processes wherein the protonmotive force is converted to redox potential, and vice versa, is a hallmark of bioenergetic systems. Uncovering the design principles for the construction of such networks and associated proton wires featuring MPCET processes advances our capability to develop efficient artificial photosynthetic systems.

\section{ASSOCIATED CONTENT}

\section{SI Supporting Information}

The Supporting Information is available free of charge at https://pubs.acs.org/doi/10.1021/jacs.0c10474.

Experimental: synthetic strategy, structural characterization, nuclear magnetic resonance data, electrochemical measurements, infrared (IR), infrared spectroelectrochemistry (IRSEC) data, and electrochemical simulations; computational: protocol, calculated redox potentials and IRSEC, and optimized Cartesian coordinates of species studied (PDF)

\section{AUTHOR INFORMATION}

\section{Corresponding Authors}

Gary F. Moore - School of Molecular Sciences, Arizona State University, Tempe, Arizona 85287-1604, United States; ๑ orcid.org/0000-0003-3369-9308; Email: gary.f.moore@ asu.edu

Sharon Hammes-Schiffer - Department of Chemistry, Yale University, New Haven, Connecticut 06520-8107, United States; orcid.org/0000-0002-3782-6995; Email: sharon.hammes-schiffer@yale.edu

Ana L. Moore - School of Molecular Sciences, Arizona State University, Tempe, Arizona 85287-1604, United States; ○ orcid.org/0000-0002-6653-9506; Email: amoore@ asu.edu

\section{Authors}

Walter D. Guerra - School of Molecular Sciences, Arizona State University, Tempe, Arizona 85287-1604, United States; orcid.org/0000-0003-0712-2740

Emmanuel Odella - School of Molecular Sciences, Arizona State University, Tempe, Arizona 85287-1604, United States; (1) orcid.org/0000-0002-7021-400X

Maxim Secor - Department of Chemistry, Yale University, New Haven, Connecticut 06520-8107, United States; (1) orcid.org/0000-0003-2569-2384 
Joshua J. Goings - Department of Chemistry, Yale University, New Haven, Connecticut 06520-8107, United States; (ㄱ) orcid.org/0000-0002-2817-1966

María N. Urrutia - School of Molecular Sciences, Arizona State University, Tempe, Arizona 85287-1604, United States; (1) orcid.org/0000-0003-4274-9688

Brian L. Wadsworth - School of Molecular Sciences, Arizona State University, Tempe, Arizona 85287-1604, United States; orcid.org/0000-0002-0274-9993

Miguel Gervaldo - Departamento de Química, Facultad de Ciencias Exactas, Físico-Químicas y Naturales, Universidad Nacional de Río Cuarto, 5800 Río Cuarto, Córdoba, Argentina; (1) orcid.org/0000-0001-9287-5872

Leónides E. Sereno - Departamento de Química, Facultad de Ciencias Exactas, Físico-Químicas y Naturales, Universidad Nacional de Río Cuarto, 5800 Río Cuarto, Córdoba, Argentina; (ㅇ) orcid.org/0000-0001-8361-7695

Thomas A. Moore - School of Molecular Sciences, Arizona State University, Tempe, Arizona 85287-1604, United States; (1) orcid.org/0000-0002-1577-7117

Complete contact information is available at: https://pubs.acs.org/10.1021/jacs.0c10474

\section{Author Contributions}

W.D.G., E.O., and M.S. contributed equally to this work.

\section{Notes}

The authors declare no competing financial interest.

\section{ACKNOWLEDGMENTS}

This research was supported by the U.S. Department of Energy, Office of Science, Office of Basic Energy Sciences, under Award DE-FG02-03ER15393 and under Early Career Award DESC0021186. The theoretical portion of this work was supported as part of the Center for Molecular Electrocatalysis, an Energy Frontier Research Center, funded by the U.S. Department of Energy, Office of Science, Basic Energy Sciences. G.F.M. acknowledges support from the Camille Dreyfus Teacher-Scholar Awards Program.

\section{REFERENCES}

(1) Barry, B. A.; Babcock, G. T. Tyrosine Radicals Are Involved in the Photosynthetic Oxygen-Evolving System. Proc. Natl. Acad. Sci. U. S. A. 1987, 84 (20), 7099-7103.

(2) Tommos, C.; Babcock, G. T. Proton and Hydrogen Currents in Photosynthetic Water Oxidation. Biochim. Biophys. Acta, Bioenerg. 2000, 1458 (1), 199-219.

(3) Blankenship, R. E. Chapter 7: Reaction Centers and Electron Transfer Pathways in Oxygenic Photosynthetic Organisms. In Molecular Mechanisms of Photosynthesis, 2nd ed.; Wiley Blackwell: Chichester, UK, 2014; pp 111-132.

(4) Umena, Y.; Kawakami, K.; Shen, J.-R.; Kamiya, N. Crystal Structure of Oxygen-Evolving Photosystem II at a Resolution of $1.9 \AA$. Nature 2011, 473 (7345), 55-60.

(5) Saito, K.; Mandal, M.; Ishikita, H. Redox Potentials along the Redox-Active Low-Barrier H-Bonds in Electron Transfer Pathways. Phys. Chem. Chem. Phys. 2020, 22, 25467-25473.

(6) Reece, S. Y.; Nocera, D. G. Proton-Coupled Electron Transfer in Biology: Results from Synergistic Studies in Natural and Model Systems. Annu. Rev. Biochem. 2009, 78 (1), 673-699.

(7) Migliore, A.; Polizzi, N. F.; Therien, M. J.; Beratan, D. N. Biochemistry and Theory of Proton-Coupled Electron Transfer. Chem. Rev. 2014, 114 (7), 3381-3465.

(8) Megiatto, J. D., Jr.; Méndez-Hernández, D. D.; Tejeda-Ferrari, M. E.; Teillout, A.-L.; Llansola-Portolés, M. J.; Kodis, G.; Poluektov,
O. G.; Rajh, T.; Mujica, V.; Groy, T. L.; Gust, D.; Moore, T. A.; Moore, A. L. A Bioinspired Redox Relay That Mimics Radical Interactions of the Tyr-His Pairs of Photosystem II. Nat. Chem. 2014, 6 (5), 423-428.

(9) Manbeck, G. F.; Fujita, E.; Concepcion, J. J. Proton-Coupled Electron Transfer in a Strongly Coupled Photosystem II-Inspired Chromophore-Imidazole-Phenol Complex: Stepwise Oxidation and Concerted Reduction. J. Am. Chem. Soc. 2016, 138 (36), 1153611549.

(10) Glover, S. D.; Parada, G. A.; Markle, T. F.; Ott, S.; Hammarström, L. Isolating the Effects of the Proton Tunneling Distance on Proton-Coupled Electron Transfer in a Series of Homologous Tyrosine-Base Model Compounds. J. Am. Chem. Soc. 2017, 139 (5), 2090-2101.

(11) Hammarström, L. Artificial Photosynthesis: Closing Remarks. Faraday Discuss. 2017, 198 (0), 549-560.

(12) Chararalambidis, G.; Das, S.; Trapali, A.; Quaranta, A.; Orio, M.; Halime, Z.; Fertey, P.; Guillot, R.; Coutsolelos, A.; Leibl, W.; Aukauloo, A.; Sircoglou, M. Water Molecules Gating a Photoinduced One-Electron Two-Protons Transfer in a Tyrosine/Histidine (Tyr/ His) Model of Photosystem II. Angew. Chem., Int. Ed. 2018, 57 (29), 9013-9017.

(13) Nilsen-Moe, A.; Reinhardt, C. R.; Glover, S. D.; Liang, L.; Hammes-Schiffer, S.; Hammarström, L.; Tommos, C. ProtonCoupled Electron Transfer from Tyrosine in the Interior of a de Novo Protein: Mechanisms and Primary Proton Acceptor. J. Am. Chem. Soc. 2020, 142 (26), 11550-11559.

(14) Zhao, Y.; Swierk, J. R.; Megiatto, J. D.; Sherman, B.; Youngblood, W. J.; Qin, D.; Lentz, D. M.; Moore, A. L.; Moore, T. A.; Gust, D.; Mallouk, T. E. Improving the Efficiency of Water Splitting in Dye-Sensitized Solar Cells by Using a Biomimetic Electron Transfer Mediator. Proc. Natl. Acad. Sci. U. S. A. 2012, 109 (39), 15612-15616.

(15) Pannwitz, A.; Wenger, O. S. Recent Advances in Bioinspired Proton-Coupled Electron Transfer. Dalt. Trans. 2019, 48 (18), 58615868.

(16) Benisvy, L.; Bittl, R.; Bothe, E.; Garner, C. D.; McMaster, J.; Ross, S.; Teutloff, C.; Neese, F. Phenoxyl Radicals Hydrogen-Bonded to Imidazolium: Analogues of Tyrosyl D. of Photosystem II: HighField EPR and DFT Studies. Angew. Chem., Int. Ed. 2005, 44 (33), 5314-5317.

(17) Markle, T. F.; Rhile, I. J.; DiPasquale, A. G.; Mayer, J. M. Probing Concerted Proton-Electron Transfer in Phenol-Imidazoles. Proc. Natl. Acad. Sci. U. S. A. 2008, 105 (24), 8185-8190.

(18) Moore, G. F.; Hambourger, M.; Kodis, G.; Michl, W.; Gust, D.; Moore, T. A.; Moore, A. L. Effects of Protonation State on a Tyrosine-Histidine Bioinspired Redox Mediator. J. Phys. Chem. B 2010, 114 (45), 14450-14457.

(19) Megiatto, J. D.; Antoniuk-Pablant, A.; Sherman, B. D.; Kodis, G.; Gervaldo, M.; Moore, T. A.; Moore, A. L.; Gust, D. Mimicking the Electron Transfer Chain in Photosystem II with a Molecular Triad Thermodynamically Capable of Water Oxidation. Proc. Natl. Acad. Sci. U. S. A. 2012, 109 (39), 15578-15583.

(20) Odella, E.; Mora, S. J.; Wadsworth, B. L.; Huynh, M. T.; Goings, J. J.; Liddell, P. A.; Groy, T. L.; Gervaldo, M.; Sereno, L. E.; Gust, D.; Moore, T. A.; Moore, G. F.; Hammes-Schiffer, S.; Moore, A. L. Controlling Proton-Coupled Electron Transfer in Bioinspired Artificial Photosynthetic Relays. J. Am. Chem. Soc. 2018, 140 (45), $15450-15460$.

(21) Odella, E.; Wadsworth, B. L.; Mora, S. J.; Goings, J. J.; Huynh, M. T.; Gust, D.; Moore, T. A.; Moore, G. F.; Hammes-Schiffer, S.; Moore, A. L. Proton-Coupled Electron Transfer Drives Long-Range Proton Translocation in Bioinspired Systems. J. Am. Chem. Soc. 2019, 141 (36), 14057-14061.

(22) Huynh, M. T.; Mora, S. J.; Villalba, M.; Tejeda-Ferrari, M. E.; Liddell, P. A.; Cherry, B. R.; Teillout, A. L.; MacHan, C. W.; Kubiak, C. P.; Gust, D.; Moore, T. A.; Hammes-Schiffer, S.; Moore, A. L. Concerted One-Electron Two-Proton Transfer Processes in Models 
Inspired by the Tyr-His Couple of Photosystem II. ACS Cent. Sci. 2017, 3 (5), 372-380.

(23) Odella, E.; Mora, S. J.; Wadsworth, B. L.; Goings, J. J.; Gervaldo, M. A.; Sereno, L. E.; Groy, T. L.; Gust, D.; Moore, T. A.; Moore, G. F.; Hammes-Schiffer, S.; Moore, A. L. Proton-Coupled Electron Transfer across Benzimidazole Bridges in Bioinspired Proton Wires. Chem. Sci. 2020, 11, 3820-3828.

(24) Rhile, I. J.; Markle, T. F.; Nagao, H.; DiPasquale, A. G.; Lam, O. P.; Lockwood, M. A.; Rotter, K.; Mayer, J. M. Concerted ProtonElectron Transfer in the Oxidation of Hydrogen-Bonded Phenols. J. Am. Chem. Soc. 2006, 128 (18), 6075-6088.

(25) Zhang, M. T.; Irebo, T.; Johansson, O.; Hammarström, L. Proton-Coupled Electron Transfer from Tyrosine: A Strong Rate Dependence on Intramolecular Proton Transfer Distance. J. Am. Chem. Soc. 2011, 133 (34), 13224-13227.

(26) Markle, T. F.; Zhang, M. T.; Santoni, M. P.; Johannissen, L. O.; Hammarström, L. Proton-Coupled Electron Transfer in a Series of Ruthenium-Linked Tyrosines with Internal Bases: Evaluation of a Tunneling Model for Experimental Temperature-Dependent Kinetics. J. Phys. Chem. B 2016, 120 (35), 9308-9321.

(27) Ren, G.; Meng, Q.; Zhao, J.; Chu, T. Molecular Design for Electron-Driven Double-Proton Transfer: A New Scenario for Excited-State Proton-Coupled Electron Transfer. J. Phys. Chem. A 2018, 122 (47), 9191-9198.

(28) Goings, J. J.; Hammes-Schiffer, S. Nonequilibrium Dynamics of Proton-Coupled Electron Transfer in Proton Wires: Concerted but Asynchronous Mechanisms. ACS Cent. Sci. 2020, 6 (9), 1594-1601.

(29) Kaljurand, I.; Kütt, A.; Sooväli, L.; Rodima, T.; Mäemets, V.; Leito, I.; Koppel, I. A. Extension of the Self-Consistent Spectrophotometric Basicity Scale in Acetonitrile to a Full Span of $28 \mathrm{PKa}$ Units: Unification of Different Basicity Scales. J. Org. Chem. 2005, 70 (3), $1019-1028$.

(30) Augustin-Nowacka, D.; Chmurzyñski, L. A Potentiometric Study of Acid-Base Equilibria of Substituted Pyridines in Acetonitrile. Anal. Chim. Acta 1999, 381 (2-3), 215-220.

(31) Odinokov, S. E.; Mashkovsky, A. A.; Nabiullin, A. A. Infrared Spectra of Pyridinium Salts in Solution-III. Associations of Pyridinium Salts with Bases. Spectrochim. Acta Part A Mol. Spectrosc. 1983, 39 (12), 1065-1071.

(32) Glazunov, V. P.; Odinokov, S. E. Infrared Spectra of Pyridinium Salts in Solution-II. Fermi Resonance and Structure of NNH Bands. Spectrochim. Acta Part A Mol. Spectrosc. 1982, 38 (4), 409-415.

(33) Wuts, P. G. M.; Greene, T. W. Chapter 7: Protection for the Amino Group. In Greene's Protective Groups in Organic Synthesis, 4th ed.; Wiley Online Books: Hoboken, NJ, 2006; pp 696-926.

(34) Liu, S.; Zhang, H.; Li, Y.; Liu, J.; Du, L.; Chen, M.; Kwok, R. T. K.; Lam, J. W. Y.; Phillips, D. L.; Tang, B. Z. Strategies to Enhance the Photosensitization: Polymerization and the Donor-Acceptor EvenOdd Effect. Angew. Chem., Int. Ed. 2018, 57 (46), 15189-15193.

(35) Pochorovski, I.; Milić, J.; Kolarski, D.; Gropp, C.; Schweizer, W. B.; Diederich, F. Evaluation of Hydrogen-Bond Acceptors for RedoxSwitchable Resorcin[4]Arene Cavitands. J. Am. Chem. Soc. 2014, 136 (10), 3852-3858.

(36) Aslan, J. M.; Boston, D. J.; MacDonnell, F. M. Photodriven Multi-Electron Storage in Disubstituted RuII Dppz Analogues. Chem. - Eur. J. 2015, 21 (48), 17314-17323.

(37) Komin, A. P.; Street, R. W.; Carmack, M. Chemistry of 1,2,5Thiadiazoles. III. $[1,2,5]$ Thiadiazolo[3,4-c] $[1,2,5]$ Thiadiazole. J. Org. Chem. 1975, 40 (19), 2749-2752.

(38) Forés, M.; Duran, M.; Solà, M.; Orozco, M.; Luque, F. J. Theoretical Evaluation of Solvent Effects on the Conformational and Tautomeric Equilibria of 2-(2'-Hydroxyphenyl)Benzimidazole and on Its Absorption and Fluorescence Spectra. J. Phys. Chem. A 1999, 103 (23), 4525-4532.

(39) Das, K.; Sarkar, N.; Ghosh, A. K.; Majumdar, D.; Nath, D. N.; Bhattacharyya, K. Excited-State Intramolecular Proton Transfer in 2(2-Hydroxyphenyl)Benzimidazole and -Benzoxazole: Effect of Rotamerism and Hydrogen Bonding. J. Phys. Chem. 1994, 98 (37), 9126-9132.
(40) Bard, A. J.; Faulkner, L. R. Electrochemical Methods: Fundamentals and Applications, 2nd ed.; John Wiley \& Sons: New York, 2001.

(41) Mora, S. J.; Odella, E.; Moore, G. F.; Gust, D.; Moore, T. A.; Moore, A. L. Proton-Coupled Electron Transfer in Artificial Photosynthetic Systems. Acc. Chem. Res. 2018, 51 (2), 445-453.

(42) Enache, T. A.; Oliveira-Brett, A. M. Phenol and ParaSubstituted Phenols Electrochemical Oxidation Pathways. J. Electroanal. Chem. 2011, 655 (1), 9-16.

(43) Li, C.; Hoffman, M. Z. One-Electron Redox Potentials of Phenols in Aqueous Solution. J. Phys. Chem. B 1999, 103 (32), 66536656.

(44) Maki, T.; Araki, Y.; Ishida, Y.; Onomura, O.; Matsumura, Y. Construction of Persistent Phenoxyl Radical with Intramolecular Hydrogen Bonding. J. Am. Chem. Soc. 2001, 123 (14), 3371-3372.

(45) Connelly, N. G.; Geiger, W. E. Chemical Redox Agents for Organometallic Chemistry. Chem. Rev. 1996, 96 (2), 877-910.

(46) Corrsin, L.; Fax, B. J.; Lord, R. C. The Vibrational Spectra of Pyridine and Pyridine-d5. J. Chem. Phys. 1953, 21 (7), 1170-1176.

(47) Wong, K. N.; Colson, S. D. The FT-IR Spectra of Pyridine and Pyridine-D5. J. Mol. Spectrosc. 1984, 104 (1), 129-151.

(48) Ureña, F. P.; Gómez, M. F.; González, J. J. L.; Torres, E. M. A New Insight into the Vibrational Analysis of Pyridine. Spectrochim. Acta, Part A 2003, 59 (12), 2815-2839.

(49) Glazunov, V. P.; Odinokov, S. E. Infrared Spectra of Pyridinium Salts in Solution-I. The Region of Middle Frequencies. Spectrochim. Acta Part A Mol. Spectrosc. 1982, 38 (4), 399-408.

(50) Cook, D. Vibrational Spectra of Pyridinium Salts. Can. J. Chem. 1961, 39 (10), 2009-2024.

(51) Lõkov, M.; Tshepelevitsh, S.; Heering, A.; Plieger, P. G.; Vianello, R.; Leito, I. On the Basicity of Conjugated Nitrogen Heterocycles in Different Media. Eur. J. Org. Chem. 2017, 2017 (30), 4475-4489. 